\title{
Obtenção de cobre eletrolítico pelo processo de eletrodeposição utilizando um banho sem cianeto e tratamento eletroquímico superficial
}

\section{Obtaining electrolytic copper by the electrodeposition process using a non-cyanide bath and surface electrochemical treatment}

\footnotetext{
${ }^{1}$ Departamento de Engenharia de Materiais, Universidade Federal de Cariri, Centro de Ciência e Tecnologia, Cidade Universitária, S/N, CEP: 63048-080, Juazeiro do Norte, Ceará, Brasil.

${ }^{2}$ Unidade Acadêmica de Engenharia Mecânica, Universidade Federal de Campina Grande, Centro de Ciência e Tecnologia, Universitário, 882, CEP: 58429-900 Campina Grande, Paraíba, Brasil.

${ }^{3}$ Unidade Acadêmica de Biologia e Química, Universidade Federal de Campina Grande, Centro de Educação e Saúde Cuité, Paraíba, Brasil.

e-mail: leonardo18.pinto@gmail.com,maria.bandeira@ufca.edu.br, cicero.santos@ufcg.edu.br, joao.agra@ufcg.edu.br, renatoacs@ufcg.edu.br
}

\section{RESUMO}

A eletrodeposição de cobre em substratos ferrosos e não-ferrosos a partir de soluções contendo cianeto é uma das formas mais utilizadas industrialmente. Os depósitos obtidos por esse processo apresentam alta qualidade com baixo custo operacional, equipamentos pouco sofisticados e pré-tratamento simples no substrato. No entanto, novos eletrólitos isentos de íons cianetos têm surgido para substituir as soluções cianídricas que são tóxicas e com grande potencial de causar danos ambientais e a saúde. O objetivo deste trabalho foi a obtenção do cobre eletrodepositado (Cu eletrolítico) por corrente contínua a partir de um banho de sulfato de amônio e citrato de sódio; e, avaliar as características deste com as do cobre eletrolítico comercial (Cu comercial), bem como analisar duas metodologias de preparação da superfície metálica para análise por microscopia. As técnicas de caracterização utilizadas foram Difração de Raios-X (DRX), Microscopia Eletrônica de Varredura (MEV), Microscopia Óptica (MO) e nanodureza, as superfícies das amostras foram preparadas por polimento convencional e eletrolítico. Observou-se que as amostras polidas eletroliticamente mostraram-se bastante brilhantes e apresentaram os contornos dos grãos com maior nitidez, os mesmos resultados não foram evidenciados pelo polimento convencional. O cobre obtido pelo banho isento de cianeto apresentou menores tamanhos de grãos e uma maior dureza dentro destes, quando comparado ao $\mathrm{Cu}$ comercial. O difratograma apresentou para o $\mathrm{Cu}$ eletrolítico picos de alta intensidade nos planos (200) e (111) mostrando uma maior orientação cristalográfica preferencial nas direções desses planos. Por fim, o MEV mostrou uma segregação de uma fase no $\mathrm{Cu}$ eletrolítico, causada pela eletrodeposição e também as formas dos grãos poligonais com microcavidades globulares do $\mathrm{Cu}$ comercial.

Palavras-chave: cobre eletrodepositado, polimento eletrolítico, banho sem cianeto.

\section{ABSTRACT}

The electrodeposition of copper on ferrous and non-ferrous substrates from solutions containing cyanide is one of the most used industrial forms. The deposits obtained by this process are of high quality with low operating cost, unsophisticated equipment and simple pre-treatment in the substrate. However, new cyanidefree electrolytes have emerged to replace cyanide solutions that are toxic and have a great potential to cause environmental and health damage. The objective of this work was to obtain electrodeposited copper (electrolytic $\mathrm{Cu}$ ) by direct current from an ammonium sulfate and sodium citrate bath; and, evaluate its characteris- 
tics with those of commercial electrolytic copper (commercial $\mathrm{Cu}$ ), as well as analyze two methodologies for preparing the metallic surface for analysis by microscopy. The characterization techniques used were X-Ray Diffraction (XRD), Scanning Electron Microscopy (SEM), Optical Microscopy (MO) and nano hardness, the sample surfaces were prepared by conventional and electrolytic polishing. It was observed that the electrolytically polished samples were very bright and showed the grain contours with greater clarity, the same results were not evidenced by conventional polishing. The copper obtained by the cyanide-free bath showed smaller grain sizes and a greater hardness inside them, when compared to commercial $\mathrm{Cu}$. The diffractogram showed high intensity peaks for the electrolytic $\mathrm{Cu}$ in the planes (200) and (111) showing a greater preferential crystallographic orientation in the directions of these planes. Finally, the SEM showed a segregation of a phase in the electrolytic $\mathrm{Cu}$, caused by the electrodeposition and also the shapes of the polygonal grains with globular microcavities of the commercial $\mathrm{Cu}$.

Keywords: electrodeposited copper, electrolytic polishing, cyanide free bath.

\section{INTRODUÇÃO}

A utilização de metais não ferrosos em várias aplicações que requerem à necessidade de características mais específicas, é cada vez mais frequente. O cobre, por exemplo, atualmente é o segundo metal não-ferroso mais usado no mundo. Destaca-se, por possuir diversas propriedades, tais como: excelente condutibilidade térmica e elétrica, resistência à corrosão e característicos de fadiga satisfatórios, boa capacidade de ser deformado, estirado e dobrado sem apresentar fissuras e perda de resistência mecânica, facilidade de fabricação e de formar ligas com outros elementos, o que permitem aplicações da indústria metalúrgica à de semicondutores [13].

O cobre é comumente utilizado como revestimento em substratos metálicos ou não metálicos em inúmeras aplicações de engenharia, onde exigem uma ampla gama de propriedades mecânicas e físicas que se estende desde propriedades superiores ao cobre forjado que possui elevada dureza, até o cobre puro recozido com elevada ductilidade e tenacidade [4]. Os revestimentos com cobre, obtidos por eletrodeposição em substratos metálicos, são frequentemente usados como recurso para proteger o metal base contra corrosão, constituir camadas intermediárias para processos de deposição de outros metais, atribuir caráter estético (fabricação de joias) e aumentar a condutividade térmica e elétrica de algumas peças [5]. A eletrodeposição desse metal também é utilizada para outras aplicações industriais como a formação de pós de cobre e eletroformação de peças [4].

A eletrodeposição do cobre pode ser realizada por intermédio de dois principais tipos de banhos: os à base de sulfato ácido e os cianetos alcalinos [5,6]. Os banhos à base de sulfato apresentam boa estabilidade química, menor toxicidade e baixo custo quando comparados com os banhos cianídricos. Apesar disso, os eletrólitos contendo cianeto são amplamente utilizados com sucesso pela indústria, tanto por necessitarem de pré-tratamento simples no substrato e equipamentos pouco sofisticados como também, pelos depósitos de cobre apresentarem características essenciais para aplicações industriais, como alta aderência e uniformidade $[4,5]$.

A maior limitação do uso dos banhos contendo cianeto é o seu alto potencial de toxicidade, exigindo grandes preocupações e imposições quanto aos aspectos ambientais e de segurança a saúde ao manuseá-los [4]. Com as medidas de segurança cada vez maiores ao uso do banho contendo cianetos, novos banhos alternativos isentos de cianetos têm sido desenvolvidos para o processo de eletrodeposição de cobre [7-10]. As vantagens desses novos banhos incluem a redução de custos com o tratamento dos efluentes, eliminação de problemas ambientais e riscos durante o manejo na produção [4]. Entretanto, a substituição total das soluções cianetadas depende, não somente dessas vantagens, mais também da competitividade de custo, qualidade do depósito e eficiência em aplicação em nível industrial, além dos eletrólitos terem de ser preferencialmente alcalinos [11].

$\mathrm{Na}$ formação de banhos alcalinos isentos de cianetos são utilizados agentes complexantes, os quais tem a função de estabilizar os íons em solução e evitar a redução espontânea desses sobre o substrato, o que produziria depósitos de cobre com pouca aderência [12]. Os agentes complexantes mais reportados em banhos alcalinos de cobre incluem o sorbitol [7], manitol [8], etilenodiaminotetracético (EDTA) [9] e citrato [10].

BARBOSA et al. [7] mostrou que a presença do sorbitol como agente complexante no eletrólito levou a formação de filme de cobre com espessura de $42 \mu \mathrm{m}$ com alta eficiência eletroquímica comparável ao dos banhos com cianeto, além de apresentarem característica brilhante com cor dourada e uniforme. Estudos da morfologia da superfície e composições químicas e de fases da liga $\mathrm{Cu}$-Zn eletrodepositada em solução alcalina composta por manitol foi realizada por JUŠKĖNAS et al. [8]. Os autores mostraram que os revestimen- 
tos com essa liga podem ser eletrodepositados usando o manitol com agente complexante de $\mathrm{Cu}$. ALMEIDA et al [9] avaliou a eletrodeposição de $\mathrm{Cu}-\mathrm{Zn}$ no aço 1010 utilizando um banho a base de EDTA. E dentre outros resultados desse estudo os depósitos eram de cor dourada, compatíveis com os requisitos ambientais e os revestimentos podem ser obtidos a partir de banhos com EDTA. LIZAMA-TZEC et al. [10] investigaram a eletrodeposição de cobre a partir de uma solução de citrato em função do $\mathrm{pH}$ do banho e aplicado pra preencher valas de $500 \mathrm{~nm}$. Os autores relataram que a morfologia dos depósitos nas valas dependia do $\mathrm{pH}$ e os melhores resultados foram obtidos com $\mathrm{pH} 3,1$.

As pesquisas que tratam dos depósitos de cobre com eletrólitos isentos de cianeto pouco exploraram as propriedades mecânicas e as características microestruturais como tamanho de grão e seus aspectos morfológicos. Necessitando assim, de mais estudos com essa abordagem para que se tenha uma total compreensão das mudanças das características com a substituição dos banhos cianídricos por outras alternativas.

O tratamento eletroquímico superficial também chamado de polimento eletrolítico é uma técnica muito útil quando pretende-se estudar as características da microestrutura de depósitos metálicos como o cobre eletrodepositado. Devido a espessura, o método convencional de preparação da superfície por etapas de lixamento, polimento (mecânico ou manual) e ataque químico não é eficiente para análises por microscopia, uma vez que pode ocorrer a remoção de muito material da camada depositada na tentativa de obter um ótimo acabamento nas amostras. Diferentemente, o polimento eletrolítico é um dos métodos de acabamento superficial de peças metálicas bastante eficiente [13]. Seu princípio consiste em fazer da peça o ânodo em uma solução e à medida que uma corrente elétrica for aplicada a superfície que contém irregularidades, diferentes alturas de picos, o filme de óxido que recobre os picos mais baixos da superfície impede a dissolução, enquanto que os mais altos, não recobertos recebem maior corrente e dissolvem-se mais rapidamente, ao final se obtém uma superfície nivelada e espelhada [14].

A importância de uma boa preparação da superfície para análise microscópica reflete direto na caracterização morfológica da microestrutura e, essa somada aos resultados de outras análises permite concluir sobre as propriedades mecânicas de um metal ou liga [15]. Neste contexto, o presente trabalho teve como objetivo obter $\mathrm{Cu}$ eletrolítico pelo processo de eletrodeposição utilizando um banho alcalino sem cianeto e avaliar dois tipos de polimento superficial, o convencional e o eletrolítico, utilizados neste estudo para as análises por microscopia e nanodureza. As características do $\mathrm{Cu}$ comercial foram determinadas e comparadas com o obtido pela eletrodeposição.

\section{MATERIAIS E MÉTODOS}

$\mathrm{O} \mathrm{Cu}$ eletrolítico foi obtido a partir da eletrodeposição, realizada sobre a superfície do substrato de $\mathrm{Cu}$ comercial com diâmetro de 12,69 mm após as amostras serem embutidas a frio, preparada com lixas de carbeto de silício com granulometria decrescente de 220 até 1200. O banho utilizado foi sem cianeto contendo os seguintes reagentes, sulfato de cobre II $0,1 \mathrm{M}$, sulfato de amônio $0,3 \mathrm{M}$ e citrato de sódio $0,3 \mathrm{M}$. A temperatura do banho eletrolítico foi de $60{ }^{\circ} \mathrm{C}$, densidade de corrente de $10 \mathrm{~mA} / \mathrm{cm}^{2}$ e $\mathrm{pH} 8,0$. O sistema de eletrodeposição utilizado consistiu em colocar o cátodo (substrato) centralizado em paralelo com um ânodo de platina, sem que houvesse contato entre ambos para depois disso, mergulhá-lo no banho eletrolítico. O ajuste da densidade de corrente foi realizado por uma fonte de corrente contínua da marca Agilent modelo E3633A. Todos os depósitos foram realizados em temperatura ambiente e em triplicata.

Para a avaliação dos aspectos microestruturais associados aos contornos de grãos foi realizado a metalografia das amostras de $\mathrm{Cu}$ comercial e eletrolítico. A preparação da superfície seguiu inicialmente a etapa de lixamento para ambas. As de Cu eletrolítico foram submetidas a um lixamento manual executado cautelosamente com uma lixa de granulometria de 1200. A utilização direta desta, não passando por intermediárias, foi em virtude da espessura do cobre obtido após a eletrodeposição, sendo que lixas com granulometrias maiores poderiam ocasionar a retirada da camada depositada. Para as de $\mathrm{Cu}$ comercial foi realizado o lixamento mecânico utilizando um equipamento da marca AROTEC modelo APL-4 sob fluxo de água constante numa sequência de lixas com granulação de 220, 320, 400, 600 e 1200.

Concluído o lixamento, metade do $\mathrm{Cu}$ comercial e também do $\mathrm{Cu}$ eletrolítico foram polidas pelo método de polimento convencional. Para o primeiro, foi empregado o polimento convencional mecânico utilizando uma politriz metalográfica da AROTEC sob rotação de $220 \mathrm{rpm}$, já o segundo foi polido manualmente usando no pano autoadesivo para ambos, pasta de alumina de $1 \mu \mathrm{m}, 0,3 \mu \mathrm{m}$ e $0,05 \mu \mathrm{m}$ obedecendo respectivamente essa ordem. $\mathrm{O}$ ataque químico de modo a revelar os contornos de grãos foi realizado com Percloreto de Ferro.

O polimento eletrolítico foi empregado nas demais amostras lixadas de ambos os cobres. O equipamento utilizado foi um eletrômetro do tipo Electromet4 Polisher/Etcher da marca BUEHLER. O eletrólito 
empregado foi o Ácido Fosfórico em água classificado como grupo (III), segundo ASTM E-1558-93 [16], com composição de 500ml de água destilada e 500ml de Ácido Fosfórico P.A. Os parâmetros utilizados para que pudesse obter uma área de $5.68 \mathrm{~mm}^{2}$ eletropolida foram definidos após várias tentativas, sendo eles: A temperatura do banho eletrolítico mantida a $26^{\circ} \mathrm{C}$ para que a viscosidade e a resistência do mesmo permanecessem constantes a fim de não perder a qualidade do polimento [15]. Tensão de $4 \mathrm{~V}$ aplicada na célula eletrolítica com duração de 1 minuto e 03 segundos, com a velocidade de agitação do eletrólito de $90 \%$ do suportado pelo equipamento.

O estudo superficial do revestimento depositado foi realizado por microscopia óptica utilizando um microscópio ótico Olympus BX51 e por microscopia eletrônica de varredura utilizando um equipamento da Tescan VEGA3 SBH equipado com Detector de EDS a seco da Oxford modelo X-ACT IE150. O tamanho de grão foi determinado pela análise de 5 imagens, atingindo a contagem de 920 grãos para cada cobre supracitado, para tanto foi utilizado o programa de imagem IMAGEJ.

As nanodurezas foram determinadas por nano-indentação com a utilização de um ultramicrodurômetro da marca Shimadzu modelo DUH-211 com penetrador Berkovitch. Com este equipamento é possível determinar e limitar a penetração do indentador nas amostras.

E para avaliar a cristalinidade do Cu foram realizados ensaios de Difração de Raios-X, para isso, utilizou-se um difratômetro de raios-X XRD-6100 da Shimadzu. Os padrões foram obtidos no modo contínuo na região de $2 \theta$ compreendida entre $30-100^{\circ}$, com passo de $0,02^{\circ}$, velocidade de $0,5^{\circ} / \mathrm{min}$, com ângulo de incidência de $3^{\circ}$.

\section{RESULTADOS E DISCUSSÕES}

Com o polimento eletrolítico foram obtidos acabamentos superficiais de alta qualidade em ambas as amostras de cobre, as mesmas se mostraram bastante brilhantes o que não ficou bem evidente com as submetidas ao polimento convencional. A análise metalográfica ratificou a eficiência desse tipo de polimento, conforme mostrado pelas micrografias da figura 1, onde é possível observar nitidamente a diferença de acabamento superficial entre os dois métodos de polimento empregado.

As microestruturas das amostras que foram submetidas ao polimento eletrolítico são apresentadas nas figura 1a e 1c, foi observado claramente os contornos de grãos do $\mathrm{Cu}$ comercial e eletrolítico, sendo possível determinar a partir desse resultado o tamanho e o aspecto morfológico dos grãos, isso por que esse método permite que as micro elevações na superfície metálica sejam removidas, havendo assim um decréscimo da rugosidade das mesmas a níveis micrométricos pela dissolução eletrolítica do metal em uma solução, e isso promove o nivelamento, brilho e refletividade da superfície do metal [15,17], deixando-o isento de riscos e definindo bem as fronteiras de grãos, além do que não há necessidade de preparar uma solução de ataque após o término do polimento. A figura $1 \mathrm{~b}$ e $1 \mathrm{~d}$ mostra a micrografia da superfície dos tipos de cobre supracitados polidos de forma convencional, nestas é possível observar a presença de riscos resultante do acabamento superficial, além do que os contornos não se apresentam delineados como os apresentados pelo polimento eletrolítico. Para metais dúcteis como é o caso do cobre, o polimento convencional não é ideal porque os riscos causados durante o lixamento são difíceis de serem retirados, conforme mostra as micrografias $1 \mathrm{~b}$ e $1 \mathrm{~d}$. 

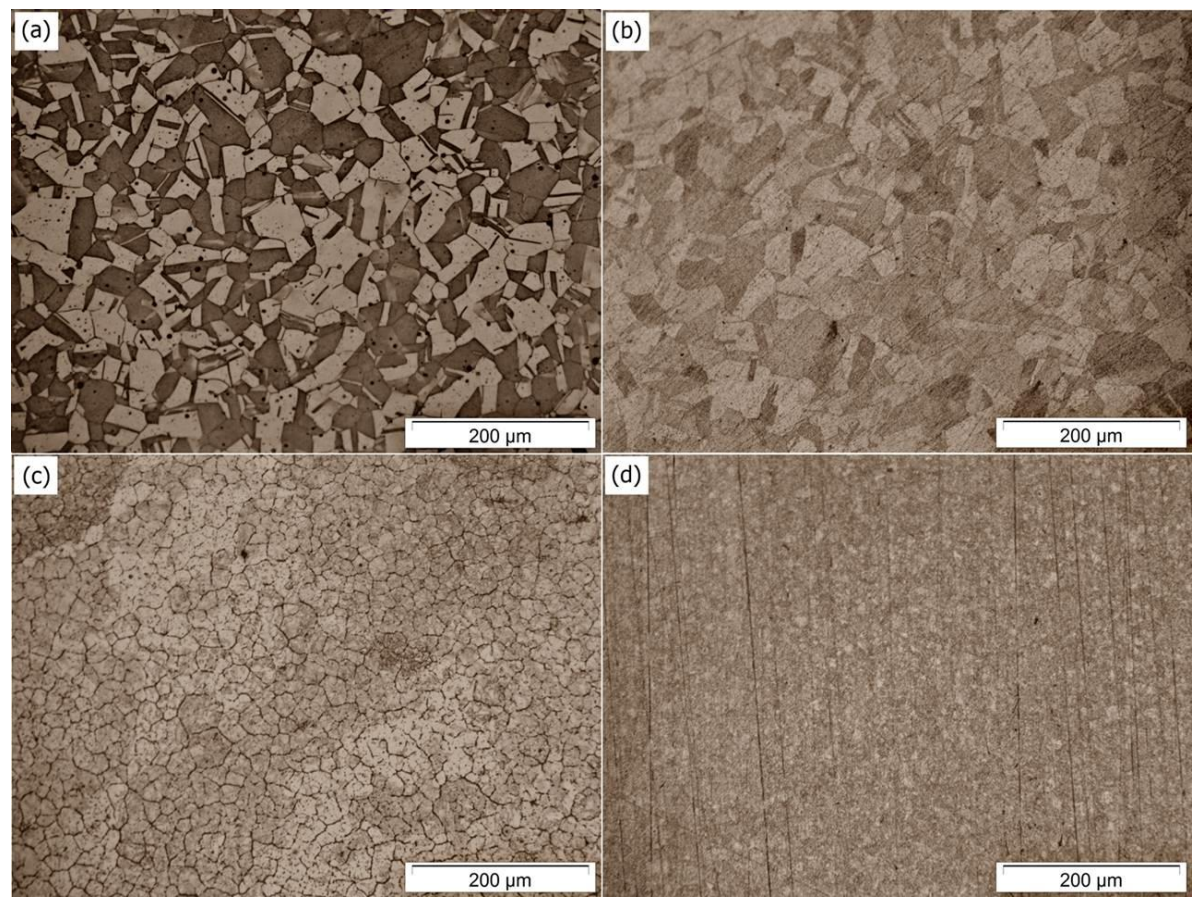

Figura 1: Micrografias do MO com aumento de 200x: a) Cu comercial com polimento eletrolítico; b) $\mathrm{Cu}$ comercial com polimento convencional; c) Cu eletrolítico polimento eletrolítico; d) Cu eletrolítico com polimento convencional.

Pelo processo de eletrodeposição sem cianeto foi obtido uma camada de cobre com espessura de aproximadamente $34 \mu \mathrm{m}$ e coloração dourada. Os aspectos da superfície dessas amostras e do Cu comercial foram determinados pelo $\mathrm{MEV}$, os resultados estão ilustrados na figura 2. Observa-se pela micrografia da figura $2 \mathrm{~b}$ uma segregação nas regiões próximas dos contornos de grãos do $\mathrm{Cu}$ eletrolítico, esta provavelmente é uma fase de Óxido Cuproso que precipitou em uma matriz praticamente isenta de oxigênio [2,18]. Isso devido à baixa ou quase nula solubilidade do oxigênio no cobre no estado sólido, conforme o diagrama de equilíbrio $\mathrm{Cu}-\mathrm{O}$ [18]. A figura $2 \mathrm{a}$ mostra a micrografia do $\mathrm{Cu}$ comercial, nesta é possível notar grãos poligonais com microcavidades globulares dispersas causadas pela remoção de material, devido a facilidade de arrancamento deste pelo polimento eletrolítico o que está ligado a presença de elementos com maior susceptibilidade a remoção nas condições que as amostras foram submetidas para preparação da superfície.

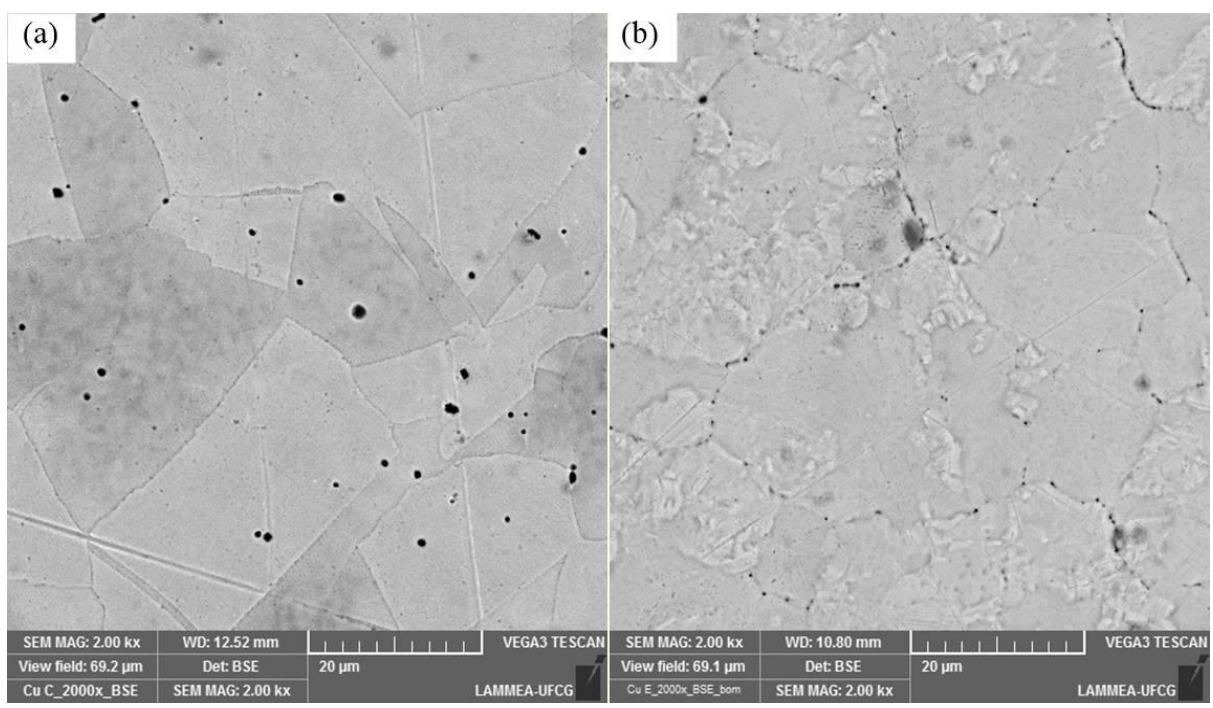

Figura 2: Micrografias (MEV) da superfície das amostras de cobre: a) Cu comercial; b) Cu eletrolítico.

É perceptível pelas micrografias a e c da figura 1 que o $\mathrm{Cu}$ eletrolítico apresenta menor tamanho de grão em relação ao comercial. Em termos numéricos, a distribuição de tamanho de grão de ambos está ilus- 
trada nos histogramas da figura 3. Para o $\mathrm{Cu}$ comercial, as maiores frequências na distribuição se encontram entre a faixa de tamanho de 20 a $40 \mu \mathrm{m}$, com ocorrência de 452 grãos, ou seja, cerca de $49 \%$ do total. Já o Cu eletrolítico foi observado no histograma 3b, que apresentou 705 grãos representando um total de 76,6\% com frequência entre 10 e $30 \mu \mathrm{m}$. Em média o Cu comercial apresentou tamanho de $40.17 \mu \mathrm{m}$ e o Cu eletrolítico apresentou tamanho de $23.24 \mu \mathrm{m}$, sendo que a redução do tamanho de grão causada pela eletrodeposição foi em torno de $57,8 \%$
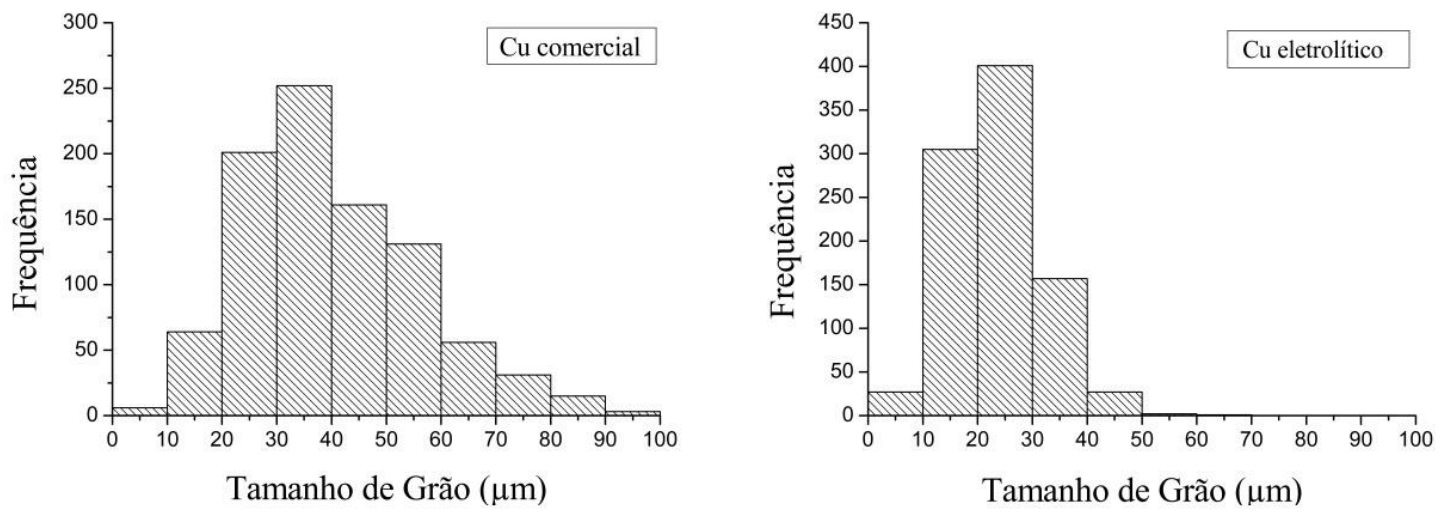

Figura 3: Histogramas das distribuições de frequências do tamanho de grão: a) $\mathrm{Cu}$ comercial; b) Cu eletrolítico.

O processo de eletrodeposição proporcionou a diminuição dos tamanhos de grãos do depósito obtido, esse resultado ocorre principalmente quando se trabalha com métodos de deposição com corrente contínua ao invés de pulsado, além do que, os grãos poderão ser ainda menores a medida que a densidade de corrente aplicada for aumentada [19, 20, 21]. Em estudo YAMASAKI [22], evidenciou que o refino do grão por eletrodeposição altera consideravelmente a resistência mecânica de um depósito metálico.

Conforme à diminuição dos tamanhos dos grãos há um aumento na área de contornos e, esses influenciam diretamente nas propriedades mecânicas de um material metálico policristalino, uma vez que, atuam como barreiras ao principal mecanismo de deformação plástica dos metais que é o movimento das discordâncias e isso tem como consequência um aumento na resistência do material. A dureza, é fortemente dependente do tamanho dos grãos [23]. Entretanto, quando se trata de nanodureza onde as indentações são realizadas em escalas nanométricas e no interior do grão, os contornos não detêm relativo efeito sobre essa propriedade. Neste caso, vários fatores podem ser responsáveis para o aumento de dureza como: fronteiras de maclas, alta ou baixa densidade de discordâncias, solução sólida, partículas de segunda fase, entre outros [24, 25, 26]. Para este estudo, onde se realizou uma eletrodeposição com corrente contínua para o Cu eletrolítico, as fronteiras de maclas apresentam-se com baixa ou nenhuma frequência nesse metal segundo SANTOS [19], não influenciando assim na sua resistência.

O resultado do ensaio de nanodureza pelo ultra-microdurômetro com nano-indentação no interior dos grãos dos tipos de $\mathrm{Cu}$ supracitado neste estudo mostrou que, o $\mathrm{Cu}$ eletrolítico apresenta uma dureza maior em relação ao $\mathrm{Cu}$ comercial, como ilustrado na tabela 1 .

Tabela 1: Valores de nanodureza em média e desvio padrão das amostras de $\mathrm{Cu}$ comercial e eletrolítico.

\begin{tabular}{c|c}
\hline AMOSTRA & NANODUREZA \\
\hline $\mathrm{Cu}$ comercial & $88,6 \pm 10,24$ \\
\hline Cu eletrolítico & $110,4 \pm 6,88$ \\
\hline
\end{tabular}

Essa diferença de dureza apresentada, possivelmente pode ser atribuída a alta densidade de discordâncias uma vez que, quando o $\mathrm{Cu}$ é eletrodepositado em um substrato, a camada depositada apresenta geralmente uma elevada densidade de discordâncias no material e que em geral se aproxima das de metais fortemente deformados plasticamente [26], sendo que a deformação é uma das formas de aumentar consideravelmente o número de discordâncias.

A partir do resultado da análise de DRX, figura 4, observa-se que ambas as amostras de cobre apresentam a mesma localização dos picos, confirmando assim pela literatura $[1,2,15,24]$ a sua estrutura crista- 
lina que é a cúbica de face centrada (CFC). O Cu comercial, apresentou apenas um pico com alta intensidade, o (111), referente a orientação cristalina principal. Já o eletrolítico apresentou dois, (111) e (200), isso mostra que a condição de difração de Bragg é mais satisfeita por um conjunto de planos cristalográficos deste último. E que a eletrodeposição utilizando banho com sulfato de amônio e citrato de sódio proporcionou um aumento na intensidade em (200), sendo este e o (111) as orientações cristalinas preferidas dos grãos no depósito obtido. Um estudo utilizando um banho contendo sulfato cobre anidro, hidróxido de sódio e sorbitol apresentou orientação cristalográfica preferida em (111), sendo o método de eletrodeposição utilizado útil para produção de cobre monofásico [6].

No difratograma do $\mathrm{Cu}$ eletrolítico, figura $4 \mathrm{~b}$, observa-se também que há um aumento na intensidade da linha de base quando comparada com a do $\mathrm{Cu}$ comercial, isso pode ser atribuído aos menores grãos apresentados pelo $\mathrm{Cu}$ eletrolítico, a segregação próxima aos contornos de grãos e a elevada densidade de discordâncias proporcionada pela eletrodeposição. A linha de base representa a fase amorfa de um material [27], no caso dos metais que normalmente formam sólidos cristalinos ela está relacionada com a fração de desordem dos átomos causado por segregação de uma fase onde há uma desorientação na interfase entre as fases presentes, e também por vários defeitos; como os interfaciais sendo as fronteiras de grãos um deles e os defeitos de linha como as discordâncias. Grãos menores aumentam as regiões de desordem cristalográfica situadas nas fronteiras e, defeitos de linha promovem um desarranjo da rede cristalina na região próxima a linha da discordância.
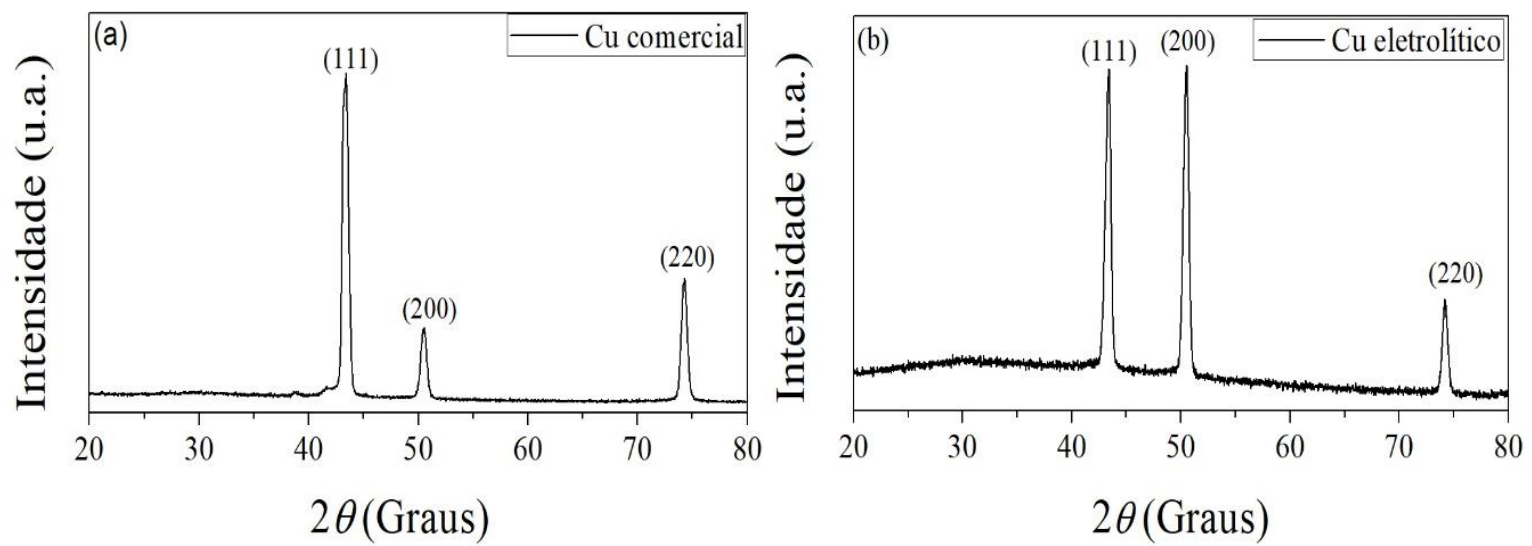

Figura 4: Difratogramas de raios-X das amostras de cobre: a) $\mathrm{Cu}$ comercial; b) Cu Eletrolítico.

\section{CONCLUSÕES}

Foi obtido com sucesso depósitos de cobre com espessura de $34 \mu \mathrm{m}$ por eletrodeposição utilizando o banho contendo sulfato de cobre, sulfato de amônio e citrato de sódio. Esses depósitos apresentam além das vantagens com a eliminação das soluções cianídricas, uma maior dureza no interior do grão quando comparado com o $\mathrm{Cu}$ comercial.

As analises de DRX mostraram que o Cu comercial apresentou orientação cristalina preferencial em (111), já o Cu eletrolítico em (200) e (111). Foi constatado pelo MEV segregação de uma fase nas regiões dos contornos de grãos desse último; e, no primeiro observou-se as formas poligonais dos grãos com microcavidades globulares dispersas.

O polimento eletrolítico mostrou ser eficiente quando comparado com o convencional para a preparação da superfície de metais dúcteis e com espessura fina, como os depósitos de cobre. As micrografias evidenciaram sua ótima eficiência, definindo bem os contornos de grãos e sem apresentar riscos causados pelo rebaixamento grosseiro das irregularidades provocadas pelo lixamento.

Por meio da eficiência do polimento eletrolítico foi possível a determinação do tamanho de grão do depósito de cobre obtido e do $\mathrm{Cu}$ comercial. Com isso constatou-se que o primeiro apresentou menor tamanho que o segundo, sendo a diferença de $57,8 \%$.

\section{AGRADECIMENTOS}

Os autores agradecem ao Laboratório de Corrosão e ao Laboratório de Metalografia e Microscopia do Departamento de Engenharia Mecânica da UFCG pelas análises. 


\section{BIBLIOGRAFIA}

[1] CHIAVERINI, V., Tecnologia Mecânica: Materiais de Construção Mecânica, 2 ed., São Paulo, McGraw-Hill, 1986.

[2] BARBOSA, C., Metais não ferrosos e suas ligas: microestrutura, propriedades e aplicações, 1 ed., Rio de Janeiro, E-Papers, 2014.

[3] ANDRADE, M. L. A., CUNHA, L.M.S., GANDRA, G.T., "O cobre brasileiro em ascensão no cenário mundial", BNDES Setorial, Rio de Janeiro, n. 13, pp. 65-94, mar. 2001.

[4] DINI, J. W., SNYDER, D. D., "Electrodeposition of copper", In: Paunovic, M., Schlesinger, M. (eds), Modern Electroplating, 5 ed., chapter 1, Hoboken (NJ), John Wiley \& Sons, 2010.

[5] SILVA, A. I. F., AFONSO, J. C., SOBRAL, L. G. S., "Avaliação do efeito da concentração de carbonato na eletrodeposição de cobre sobre discos de aço-carbono", Química Nova, v. 31, n. 7, pp. 1843-1850, November. 2008.

[6] ABDEL HAMID, Z., ABDEL AAL, A., "New environmentally friendly noncyanide alkaline electrolyte for copper electroplating", Surface \& Coatings Technology, v. 203, n. 10-11, pp. 1360-1365, November. 2009.

[7] BARBOSA, L. L., ALMEIDA, M. RH., CARLOS, R. M., et al., "Study and development of an alkaline bath for copper deposition containing sorbitol as complexing agent and morphological characterization of the copper film". Surface and Coatings Technology, v. 192, n. 2-3, pp. 145-153, March. 2005.

[8] JUŠKĖNAS, R., KARPAVIČIENĖ, V., PAKŠTAS, V., et al., "Electrochemical and XRD studies of CuZn coatings electrodeposited in solution with D-mannitol". Journal of Electroanalytical Chemistry, v. 602, n. 2, pp. 237-244, April. 2007.

[9] DE ALMEIDA, M. R. H., BARBANO, E. P., DE CARVALHO, M. F., et al., "Electrodeposition of copper-zinc from an alkaline bath based on EDTA". Surface and Coatings Technology, v. 206, n. 1, pp. 95-102, October. 2011.

[10] LIZAMA-TZEC, F. I.; CANCHÉ-CANUL, L.; OSKAM, G. "Electrodeposition of copper into trenches from a citrate plating bath", Electrochimica acta, v. 56, n. 25, pp. 9391-9396, October. 2011

[11] CASAGRANDE, D. F. M., OLIVEIRA, C. T., MALFATTI, C. F., et al., "Estudo de camadas eletrodepositadas a partir de soluções livres de cianeto", Rem: Revista Escola de Minas, v. 63, n. 2, pp. 307-313, April-june. 2010.

[12] CUNHA, M. T., JOHANN, J., FURUMURA, P. L. G. C., et al., "Estudo da eletrodeposição de cobre em meio alcalino com uso de corrente pulsada" Revista Virtual de Química, v. 6, n. 2, pp. 258-278, December. 2014.

[13] RIEDER, E. S., "Estudo da otimização das soluções de ácidos sulfúrico e fosfórico para o eletropolimento do aço ABNT 301", Dissertação de M.Sc., UFRGS, Porto Alegre, 1990.

[14] LEE E.-S., "Machining characteristics of the electropolishing of stainless steel (STS316L)". The International Journal of Advanced Manufacturing Technology, v.16, pp. 591-599, 2000.

[15] COUTINHO T. A., Metalografia de não-ferrosos: análise e prática, 1 ed., São Paulo, Edgard Blücher, 1980.

[16] AMERICAN SOCIETY FOR TESTING AND MATERIALS. ASTM E 1558 - 93: Standard guide for electrolytic polishing of metallographic specimens, pp. 917-928, 1993.

[17] VEROLI A. B., Estudo do eletropolimento galvanostático de aço inoxidável AISI 304 utilizando soluções ácidas concentradas, Dissertação de M.Sc., UFSCar., São Carlos, 2011.

[18] HELLER, W., "Copper-Based Alloys”, In: R.W. Cahn, P. Haasen, E.J. Kramer (eds.), Materials science and technology: A Comprehensive Treatment, v. 8: Structure and properties of nonferrous alloys (a cura di K.H. Matucha), 1 ed., chapter 06, New York, VHC Weinheim, 1996.

[19] SANTOS, R., Estabilidade Térmica de Materiais Nanoestruturados, Tese de D.Sc., FEUP, Portugal, 2014.

[20] MAJIDI, M. R., ASADPOUR-ZEYNALI, K., HAFEZI, B., "Reaction and nucleation mechanisms of copper electrodeposition on disposable pencil graphite electrode", Electrochimica Acta, v. 54, n. 3, pp. 11191126, January. 2009.

[21] IBAÑEZ, A., FATÁS, E., "Mechanical and structural properties of electrodeposited copper and their relation with the electrodeposition parameters", Surface \& Coatings Technology, v. 191, n. 1, pp. 7-16, February. 2005. 
[22] YAMASAKI, T., "High-strength nanocrystalline Ni-W alloys produced by electrodeposition and their embrittlement behaviors during grain growth", Scripta Materialia, v. 44, n. 8, pp. 1497-1502, January. 2001.

[23] REED-HILL, R. E., Princípios de metalurgia física, 2 ed., Rio de Janeiro, Guanabara Dois S.A., 1982.

[24] CALliSTER Jr, W. D., RETHWISCH, D. G., Ciência e Engenharia de Materiais: Uma introdução, 9 ed., Rio de Janeiro, LTC, 2016.

[25] HULL, D., BACON, D. J., Introduction to Dislocations, 4 ed., Boston, Butterworth-Heinemann, 2001.

[26] PAUNOVIC, M., SCHLESINGER, M., SNYDER, D. D., "Fundamental Considerations", In: Paunovic, M., Schlesinger, M. (eds), Modern Electroplating, 5 ed., chapter 1, Hoboken (NJ), John Wiley \& Sons, 2010.

[27] CULLITY, B. D., Elements of X-Ray Diffraction, 2 ed., Reading (Massachusetts), Addison-Wesley, 1978.

\section{ORCID}

Leonardo Alves Pinto

Maria das Dores Bandeira Barroso

Cicero de Lima Santos

João Baptista da Costa Agra de Melo

Renato Alexandre Costa de Santana https://orcid.org/0000-0002-0371-7424

https://orcid.org/0000-0002-7445-4473

https://orcid.org/0000-0003-4847-3328

https://orcid.org/0000-0002-1577-8590

http://orcid.org/0000-0002-7075-7709 